\title{
A comparison of personality characteristics and copping styles in self-immolation patients and normal in imam khomeini hospital in kermanshah
}

\begin{abstract}
Introduction: This Study aimed to compare between personality traits and coping strategies in self-immolation patients and non- self-immolation group in emam Khomeini Hospital of Kermanshah.

Materials \& methods: This research was a causal-comparative (post facto) study. In which 200 patients were hospitalized ( $\mathrm{n}=100$ self-immolation and 100 non self-immolation) the research sample was selected by in-reach sampling method. Evaluation tools included The NEO-PTR Questionnaire and Lazarus \& Folkman ${ }^{1}$ coping strategies questionnaire. For data analysis, multivariate analysis of variance (MANOVA) was used.

Findings: Patients with self-immolation showed significant higher personality traits in comparison with control group $(\mathrm{P}<0.001)$. Also Patients with self-immolation showed higher use emotion-focused coping strategies and lower use problem-focused coping strategies in comparison with control group.

Discussion \& conclusion: Although patients with self-immolation have different personality characteristics compared with non-self-immolation group and these properties have a significant effect on their copying strategies, but copying strategies could change and improve by training and need to special consideration in treatment programs.
\end{abstract}

Volume 9 Issue I - 2018

\author{
Pegah Bahramian \\ Department of Psychology, Islamic Azad University, Iran
}

Correspondence: Pegah Bahramian, Department of Psychology, Faculty of Psychology, Islamic Azad University, Kermanshah, Iran, Email p.bahramian 12@gmail.com

Received: January 05, 2017| Published: January 10, 2018

Keywords: suicide, personality traits, coping styles

\section{Introduction}

Suicide is a major health related issue. ${ }^{2}$ Every year, one million people lose their lives as a result of committing suicide. ${ }^{3}$ The spectrum of suicidal behaviors includes a range of suicidal thoughts, suicide threat, attempting suicide and complete suicide. Burning has a very deep impact on the lives of patients and interrupts their physical, mental, social and moral welfare. ${ }^{4} \mathrm{~A}$ major portion of people who commit suicide suffer from personality disorders. In this regard, personality can be considered as the most important subject in the field of psychology. Psychologists have introduced several ways for comprehension of complexity of human personality. The fivefactor model implies that human personality is consisted of five main features which include neuroticism, extroversion, acceptance, agreement and dutifulness. ${ }^{5}$ There exists a positive correlation between the psychological factor of extroversion and avoidance and seeking for social support. There also exists a negative correlation between the former and responsibility. In addition, there lies a positive correlation between personality factors of adaptability and contrastive strategies of continence and seeking social support. ${ }^{6}$ With respect to the fact that this sheds light on existence of relation and difference in personality features and coping styles, it should be considered that different humans have different evaluations of stressful situations and their manners of coping with psychological stresses differ. In fact, different humans' behaviors and responses in these situations depend on their existing coping skills and social support. ${ }^{7}$ Rezaei and Fadaei carried out a research on 220 male and females and their obtained results indicated that there existed a significant relation between personality features and problem-focused and emotionfocused coping styles. ${ }^{8}$ On the other hand, the results of research carried out by Enayati et al., ${ }^{9}$ indicated that there exists a significant difference between self-immolation patients and normal patients in terms of general health, social support and their related components. ${ }^{9}$ In a study performed by Liber et al., ${ }^{10}$ it was turned out those patients with burns had majorly made use of their emotion-focused coping style. The point that should be taken into account here is that, coping styles are considered as self-immolation predisposing factors. When people don't have efficient strategies for coping with different situations, they commit self-immolation. ${ }^{9}$ Shakeri et al., ${ }^{11}$ have stated that people who commit suicide compared to control group, are more introverted, neuroticism and psychosis. Also before committing suicide, they had been through more stressful situations and also they have made less frequent uses of their problem solving-focused coping style. ${ }^{11}$ Dolan et al. revealed that neuroticism has appositive correlation with negative interactions and that agreeableness and experiencing have a negative correlation with negative interactions. In addition, Amir-Kahn, Reisinger and Sovikert performed a study and concluded that people who possessed high levels of extroversion were able to cope against the challenges of everyday life better than people who possessed lower levels of extroversion. Also extrovert people were more susceptible for social support which would help them in terms of coping with so-called challenges. ${ }^{12}$ Patients who commit self-immolation suffer from several physical damages and also the consequences of this action are long-lasting and require a lot of effort in order to be prepared. Many people and patients may feel a lack of efficiency as a result of being mandated to use medical prescriptions. This issue has negative effects on their personality and their psychological features. ${ }^{13}$ Strict medicinal diets increase the risks of psychological illnesses such as reduced self-esteem, personality weakness and inefficient use of coping styles. ${ }^{14}$ Mental, social, personal and economic consequences of self-immolation can help us recognize factors which are beneficial in terms of avoiding this action. It is worth mentioning that with respect to investigations of the researcher, there are a few other domestic or international researches 
which have addressed the same issue and most of existing researches in this context are limited to descriptive and sociological features. In addition, in these papers, people who commit self-immolation and normal people are less frequently compared in terms of personality features and coping styles. On this basis, the present research is totally new in this aspect. In addition, the purpose of the current research is to investigate the components of personality and coping styles among people who commit self-immolation and normal people.

\section{Materials and methods}

Considering the goal of the research, this study is an applied study and it is also performed in a comparative fashion. The population of this study includes the entire patients with burns (self-immolation and normal) who had committed self-immolation during 2014-15. Among the population, 200 patients hospitalized in burn unit of Imam Khomeini hospital (100 self-immolation patients and 100 normal patients) were selected as the sample of research. For carrying out this study, first the necessary authorizations were granted from related authorities. Afterwards, the approximate number of normal burned patients and self-immolating burned patients of Imam Khomeini hospital was recorded for a 6 month period. In the next step, for selecting the patients the researcher has made presence in the hospital. In order to collect the required information, the researcher has first made contact with subjects and given them the necessary explanations regarding the questionnaires and the reason for selecting a specific subject. Afterwards, subjects filled out the questionnaires related to personality components and coping styles. After this, goals of the research were explained for the subjects and after that the subjects were agreed to participate considering the confidentiality of their information; the subjects were asked to ask the researcher for more information in case of any ambiguity regarding questionnaires. It is noteworthy that considering the physical status of patients, no time limits were applied for completing the questionnaires. For people who were under-literate or illiterate and people with unsuitable physical statuses, questionnaires were read aloud. Ultimately, after collection of required data, the data were analyzed by making use of descriptive statistical methods including mean, standard deviation and inferential statistics such as MANOVA. Measurement instruments included the following tests: 1 - the short version of NEO personality questionnaire: the personality questionnaire developed by Costa Mc. Kerry (1985) was normalized by Kiamehr in 2003. This 60 questions questionnaire is used for evaluation of five factors of personality including neuroticism, extroversion, openness, adaptability and responsibility. In this form, there are 12 questions for each factor. Also in terms of reliability of this questionnaire, it should be stated that creators of this questionnaire performed their study (2006) on a 1000 individual sample and calculated the following coefficients of Cronbach's alpha for each factor: 0.92 for neuroticism; 0.89 for extroversion; 0.87 for openness; 0.86 for adaptability and 0.90 for responsibility. For evaluation of the Persian version of this questionnaire, the test was run on subjects 7 months after the first test. Results revealed a range of correlation coefficient of 0.76 to 0.83 (Hagh Shenas, 2007). In addition, the long-term reliability of the NEO-PIR test was measured. A 6 year longitudinal study on factors of openness, extroversion and neuroticism has shown a reliability range of 0.68 to 0.83 for both personal and couple reports. This questionnaire includes 6 questions arranged based one five degrees Likert scale and is scored as follows: 0 for completely disagree, 1 for disagree, 2 for neutral, 3 for agree and 4 for completely agree. The reliability of this questionnaire for the mentioned research was calculated as 0.82 .

Questionnaire of coping with stressful (challenging) situations: in order to investigate coping styles, the questionnaire of coping styles developed by Lazarus and Folk man (1988) was implemented which included 66 questions. This questionnaire evaluates 8 coping styles. These eight-fold models are divided into two categories of problemfocused methods (seeking social support, responsibility, thoughtful solvation of problems and positive re-evaluation) and emotionfocused methods (confronting coping, avoidance, continence and escaping). Scores of this questionnaire are given in two methods of raw and relative. Raw scores describe the contrastive effort for each of the mentioned eight types of coping. In this case, the sum of answers of the subject to materials is considered as the index. Relative scores however, indicate the ratio of the effort in each type of coping. Folk man and Lazarus have carried out a study and reported the following values: reliability (internal consistency):0.75; reliability of the related sub-scales: 0.61 and positive re-assessment: 0.76 (Lazarus and Folkman 1988). The reliability of this questionnaire in the mentioned research was calculated as 0.79 .

\section{Findings}

The participants of this research included 200 individuals (100 self-immolating patients and 100 normal burned patients). This research has shown that the families of self-immolating patients are more populated and they usually have more than four children. This research has also shown that $92 \%$ of self-immolating patients have committed self-immolation in their homes. However, among normal patients, only 66 percent of the accidents were happened in their homes. In addition, findings have shown that people who commit selfimmolation mostly use oil for doing so. Reviewing the information cited on Table 1 reveals that 63 of the normal patients were males and 37 of them were females. However, in terms of the self-immolating group, 78 of the patients were females and 22 of them were males. Most of the patients of the self-immolating group were females (78\%). But for the normal patients, the number of male patients was $63.85 \%$ of the self-immolating group were married, $15 \%$ were single. This is while $60 \%$ of the normal patients were married and 40 percent were single. In addition, $26 \%$ of the normal patients were under 10 year old children. The most frequent age group was related to 21-30 and 41-50 years with $30 \%$. In terms of the self-immolating group, the highest frequency was attributable to the age group of 21-30 years with $50 \%$. As you can see in Table 2, in terms of education, the most frequency among the normal patients was attributable to illiterate people with $30 \%$. However, in terms of the self-immolating group, the most frequency was attributable to patients with high-school education with $39 \%$. Findings cited on Table 3, indicate that 62 percent of the normal patients were in suitable economic situations (having an income between 0.5 and 1.2 million tomans). This was while 65 percent of the self-immolating patients were in weak economic statuses (having an income less than 0.5 million tomans).

Tablel Abundance distribution of gender and marriage status among selfimmolating and normal patients

\begin{tabular}{|c|c|c|c|}
\hline Personal Features & Group & Abundance & Percentage \\
\hline \multirow{4}{*}{ Gender } & \multirow{4}{*}{$\begin{array}{l}\text { Self-immolating: male and } \\
\text { female. Normal: male and } \\
\text { female }\end{array}$} & 78 & $78 / 0$ \\
\hline & & 22 & $22 / 0$ \\
\hline & & 37 & $37 / 0$ \\
\hline & & 63 & $63 / 0$ \\
\hline \multirow{4}{*}{ Marriage status } & \multirow{4}{*}{$\begin{array}{l}\text { Self-immolating: single } \\
\text { married. Normal: single } \\
\text { married }\end{array}$} & 15 & $15 / 0$ \\
\hline & & 85 & $85 / 0$ \\
\hline & & 60 & $60 / 0$ \\
\hline & & 40 & $40 / 0$ \\
\hline
\end{tabular}


Table 2 Abundance distribution of education level among self-immolating and normal patients

\begin{tabular}{llll}
\hline Education & Group & Abundance & Percentage \\
\hline \multirow{2}{*}{ Illiterate } & Self-immolating & 26 & $26 / 0$ \\
& normal & 30 & $30 / 0$ \\
Elementary school & Self-immolating & 28 & $28 / 0$ \\
& normal & 24 & $24 / 0$ \\
Guidance school & Self-immolating & 3 & $3 / 0$ \\
& normal & 17 & $17 / 0$ \\
High-school & Self-immolating & 39 & $39 / 0$ \\
\multirow{2}{*}{ Semi B.A } & normal & 19 & $19 / 0$ \\
& Self-immolating & 0 & $0 / 0$ \\
B.A & normal & 5 & $5 / 0$ \\
& Self-immolating & 1 & $1 / 0$ \\
& normal & 3 & $3 / 0$
\end{tabular}

Table 3 economic status among normal and self-immolating patients

\begin{tabular}{llll}
\hline Economic Status & Group & Number & Percentage \\
\hline \multirow{2}{*}{ Weak } & Self-immolating & 65 & $65 / 0$ \\
& normal & 34 & $34 / 0$ \\
Normal & Self-immolating & 33 & $33 / 0$ \\
& normal & 62 & $62 / 0$ \\
Good & Self-immolating & 2 & $2 / 0$ \\
& normal & 3 & $3 / 0$ \\
Excellent & Self-immolating & 0 & $0 / 0$ \\
& normal & 1 & $1 / 0$
\end{tabular}

As you can see in Table 4, the average and standard deviation of the score of five-fold factors of personality is different among normal and self-immolating patients. This shows that in terms of neuroticism, elf-immolating patients have obtained a higher score compared to normal patients. The self-immolating group had lower levels of extroversion (mean: 29.47) and they had less compatibility and adaptability with external situations (mean: 23.76). Also in terms of the components of openness and responsibility, the self-immolating group has obtained a lower score compared to the control group (Table 4). As it is evident in Table 4, the average and standard deviation of the score of problem-focused style is respectively equal to 38.81 and 11.56 for the self-immolating group. This is while for normal patients, these values are respectively 48.26 and 14.81 . Ultimately, the mean and standard deviation of the score of emotion-focused style for the self-immolating group are respectively 79.47 and 16.05 . This is while for the normal patients these values are respectively51.64 and 13.05 . This shows that self-immolating people mostly use emotion-focused coping style in case of confronting problems.

Table 4 Average and standard deviations of scores of components of personality and coping styles among the studies groups

\begin{tabular}{llll}
\hline Variables & Statistical Indices & $\begin{array}{l}\text { Group } \\
\text { Self-Immolating }\end{array}$ & Normal \\
\hline Neuroticism & Average & $85 / 41$ & $25 / 28$ \\
& S.D & $56 / 10$ & $41 / 7$ \\
extroversion & Average & $47 / 29$ & $64 / 38$ \\
Adaptability & S.D & $05 / 11$ & $25 / 13$ \\
& Average & $76 / 23$ & $78 / 37$ \\
Openness & S.D & $56 / 8$ & $91 / 13$ \\
& Average & $22 / 27$ & $93 / 33$ \\
Responsibility & S.D & & $02 / 12$ \\
\multirow{2}{*}{ Problem-focused style } & Average & $65 / 30$ & $48 / 35$ \\
& S.D & $11 / 10$ & $39 / 11$ \\
Emotion-based style & Average & $81 / 38$ & $26 / 48$ \\
& S.D & $56 / 11$ & $81 / 14$ \\
& S.D & $47 / 79$ & $64 / 51$ \\
& & $05 / 16$ & $05 / 13$
\end{tabular}

Results of the Table 5 indicate that significance value of all tests authorize the possibility of making use of MANOVA. These results also show that there exists a significant difference at least for one of the dependent variables. Therefore, for identification of the source of these changes, an ANOVA variable analysis was performed within the MANOVA analysis. Results are shown in Table 6. As you can see in Table 6, there exists a significant difference between scores of indexes of components of personality and coping styles among the self-immolating and normal patients groups.

Table 5 Results of MANOVA on average scores of subjects in terms of variables of components of personality and coping styles

\begin{tabular}{|c|c|c|c|c|c|c|}
\hline & Test Name & Value & $\mathbf{F}$ & Df Hypothesis & Df Error & Sig. \\
\hline \multirow{4}{*}{ Group } & Pillay effect & $497 / 0$ & $93 / 42$ & 2 & 87 & $001 / 0>P$ \\
\hline & Wilks Lambda & $503 / 0$ & $93 / 42$ & 2 & 87 & $001 / 0>P$ \\
\hline & Hotelling effect & $987 / 0$ & $93 / 42$ & 2 & 87 & $001 / 0>P$ \\
\hline & Largest root & $987 / 0$ & $93 / 42$ & 2 & 87 & $001 / 0>P$ \\
\hline
\end{tabular}

Table 6 Results on ANOVA in MANOVA for average scores of components of personality and coping styles

\begin{tabular}{|c|c|c|c|c|c|}
\hline \multirow{2}{*}{$\begin{array}{l}\text { Variable } \\
\text { Neuroticism }\end{array}$} & \multicolumn{2}{|c|}{ Sum of Squaresf.D } & \multicolumn{2}{|c|}{ Average Squares F } & \multirow{2}{*}{$\begin{array}{l}\text { SIG } \\
001 / 0\end{array}$} \\
\hline & $37 / 629$ & $\mathrm{I}$ & $37 / 629$ & $15 / 32$ & \\
\hline Extroversion & $17 / 344$ & I & $17 / 344$ & $88 / 56$ & $001 / 0$ \\
\hline Adaptability & $19 / 428$ & 1 & $19 / 428$ & $|6 / 4|$ & $001 / 0$ \\
\hline Openness & $08 / 397$ & I & $08 / 397$ & Aug-52 & $001 / 0$ \\
\hline Responsibility & $22 / 728$ & I & $22 / 728$ & $66 / 45$ & $00 \mathrm{I} / 0$ \\
\hline \multicolumn{2}{|c|}{ Problem-focused style 68/654 } & 1 & $68 / 654$ & $33 / 42$ & $001 / 0$ \\
\hline \multicolumn{2}{|c|}{ Emotion-focused style 88/52I } & I & $88 / 521$ & $87 / 38$ & $001 / 0$ \\
\hline
\end{tabular}

\section{Discussion \& conclusions}

The purpose of this research was to compare the components of personality and coping styles among the self-immolating and normal burned patients of Imam Khomeini Hospital in the city of Kermanshah. Results of MANOVA analysis indicate that there exists a significant difference among five-fold components of personality between normal and self-immolating patients. Results of this study are consistent with the results obtained by Boyer, Lee B. et al. ${ }^{15,16}$ In order to explain the finding that addressed a significant difference between self-immolating and normal patients in terms of five-fold components of personality; it can be stated that according to current psychological theories and the literature of the subject, there exists a significant relation between negative incidents and disorders. Also the relation between committing suicide and negative incidents is justifiable in this regard. It means that negative incidents act as a source of stress and put a large amount of pressure on the individual. If these stresses are continued and prolonged for a significant amount of time, then inspite of their effects on the immune system of the body, they will also affect the psychological balance of the individual. In addition, these physical and mental disorders themselves cause an intention towards suicidal behaviors and thoughts. ${ }^{17}$ Therefore, it can be said that for people who lack efficient coping capabilities, negative incidents of life can cause disorders and orient them towards suicidal thoughts and behaviors. This claim is the result of researches performed on the families of youths who have committed suicide. These families have signs of prolonged and complex problems and issues including divorce, conflict, romantic failures, emotional issues, weak relations, lack of access to parents, high expectations of parents, mental disorders among members of family, unemployment, suicide among other members of the family and financial and economic problems. ${ }^{18}$ Another explanation regarding this research is the existence of differences between people. According to the theory of Aisenk, a portion of the difference in the process of sociability is the result of 
personal differences. These differences are the combined effects of natural factors and quantifiable personality features (neuroticism, high extroversion and etc.). ${ }^{19}$ According to the theory of Aisenk, it can be referred to neurotic conditioning among introvert personalities who deny their own tendencies and bow to the mandates of the environment. In other words, personal differences may be the result of personality and genetic traits which have high impacts on thoughts, emotions and behaviors including orientation towards anxiousness. Large personality factors provide us with strict and universal theoretical basics for determination of personal differences. Carnie and Broad burry believe that some personal tendencies such as inconsistency of emotions or neuroticism lead to sustained vulnerabilities which affect the manner of individuals' coping with stressful experiences. ${ }^{20}$ Since the behavior of human is the result of interaction between personality features and social and materialistic status of the environment; therefore personality features gain fundamental importance in terms of personal differences and personalities of individuals and their behaviors. Results of the MANOVA analysis which are evident in tables indicate that there exists a significant difference between components of emotion-focused and problem-focused coping styles among self-immolating and normal patients. For explaining this finding that states that there exists a a significant difference between components of emotion-focused and problem-focused coping styles among self-immolating and normal patients; it can be said that by making use of the problem-focused coping style, the individual uses his or her cognitive skills for solvation of problems. On this basis, ways of confronting the problem are directly assessed and usually a psychological satisfaction is obtained through finding a suitable solution for that specific problem. People, who make use of problemfocused coping style, are in fact equipped with necessary requirements for an active coping with stressful situations. This situation requires the entire abilities of an individual for a positive coping and solvation of problem and ultimately increases his or her chance of success. Therefore, the problem-focused coping style increases individuals self-confidence and in this way, it improves their problem solving capacity and ultimately, increases their satisfaction. ${ }^{21}$ Another feature of people and individuals who make use of problem-focused coping style is having low levels of stress. Having a low level of emotional stress makes the individual able to use his or her cognitive skills for coping with different problems under the light of a solicited atmosphere. Different people have different evaluations of stressful conditions and responses which these people show depend on their contrastive and coping skills as well as existing social supports. Crisis coping is a learnt behavior which should progress according to age and psychological maturity. In other words, the process of coping with stresses during the childhood is mostly emotion-based and as people age, coping methods change. On the other hand, it should be considered that upon completion of growth and reduction of growth related alterations, most people stick to a certain and constant coping style while confronting stressful situations. ${ }^{10,12}$ Erickson $^{22}$ in his psycho-social theory, believes that complete solutions of crises in human's eight stages of life, leave the individual with a legacy of coping sources which empower the person for solvation of his or her life's crises. Individuals' problem-focused coping style is a method of contrasting which is learnt through education and observation of suitable and appropriate behavioral models. People who lack these models and also lack a suitable social status, make less frequent uses of this style, and as a result, they are highly susceptible of committing suicide in different ways. There exist a significant difference between the components of personality and styles of problem solving among self-immolating and normal burned patients. In addition, significant difference lies among self-immolating patients in terms of components of personality. They mostly make use of emotion-focused problem solving rather than problem-focused problem solving. Although that difference lies between self-immolating patients and these differences have a large impact on their problem coping styles, but coping styles are still alterable through education and we are required to consider for these educations and reformations in therapies of these patients. ${ }^{23}$

\section{Acknowledgements}

This article is extracted from the M.A thesis. By this means we appreciate the collaborations and cooperation of the entire workers and authorities of Kermanshah Imam Khomeini hospital as well as patients held in burns ward of this hospital.

\section{Conflicts of interest}

None.

\section{Funding}

None.

\section{References}

1. Folkman S, Lazarus RS, Gruen RJ, et al. Appraisal, coping, health statues, and psychological symptoms. J Perso Soci Psych. 1986;50(3):571-579.

2. Nock MK, Banaji MR. Prediction of suicide ideation and attempts among adolescents using a brief performance-based test. J Consul and Clin Psych. 2011;75:707-715.

3. Grzywa A, Kucmin A, Kucmin T. Suicide problems-epidemiology, factors, motives and prevention. Pol Merkur Lekarski. 2010;27:432-436.

4. Thombs BD, Notes LD, Lawrence JW, et al. From survival to socialization: a longitudinal study of body image in survivors of severe burn injury. J Psychosoma Res. 2008;64(2):205-212.

5. Mccrae RR, Costa PT. A contemplated revision of NEO Five Factor inventory. Personality and Individual Differences. 2004;36:587-596.

6. Rostami AM, Ahadi H, Cheraghaligol H. Predict coping strategies based on personality traits dependents drugs. J Subs Abuse Addic Stud. 2014;26:111-126.

7. Frydenberg E. Adolescent Coping Theoretical and Research Perspectives. London \& New York: Principles of internal medicine, USA. 2008.p.87-91

8. Saroghad S, Rezaee AM, Fadaeedolat A. Personality characteristics and coping strategies and mental well-being of teachers]. $J$ New findings in psych. 2012;2:23-29.

9. Enayati M, Heydari A, Malekzadeh M, et al. Compare general health, self-esteem and social support in patients hospitalized for suicide, and Ghyrkhvdsvz burn Chrvmy city Ganaveh. J Gift of knowledge. 2007; 1:84-92.

10. Liber JM, Faber AW, Treffers A, et al. Coping style, personality and adolescent adjustment 10 years post -burn. Journal of Family Psychology. 2008;34:775-782.

11. Shakeri J, Parvizifard AA, Sadeghi KH, et al. Personality traits, stress, coping strategies and religious attitudes among suicide attempters. $J \mathrm{Sci}$ Res Behbood. 2006;7:43-51.

12. Hoseini Z, Kholghi Z, Somayeh J, et al. Compare couples conflicting personality traits normal person using the NEO Personality Inventory 5 factors. J Forensic Med. 2014;4(1):165-173.

13. Wildermuth AS. Cognitive behavior group therapy for adolescents with type 1 diabetes. Dissertation for Ph.D in Psychology, Regent University, USA. 2008. p.225-229.

14. Frese M. Coping as a moderator and mediator between stress at work and psychosomatic complains. Plenum Press, USA. 2013. p.124-132. 
15. Boyers E, Kenya RU, charles SC, et al. Big five personality and relationship construct material adjustment. J Adol Heal. 2014;46:592-599.

16. Lee-Bagley D, Preece M, Delgonis A. Coping with interpersonal stress: role of big five traints. The Canad J Psychia. 2005;54:521-539.

17. Akhavan F. Check attitudes and control students on the issue of suicide. Tarbiat Modares University. Abstracts of articles first seminar on mental health of students. 2001;8:55-68.

18. Mehran N. Describes the characteristics of psychological, social suicide attempters compared with normal individuals in Birjand. Thesis of M.A. Iran Uni Psychia Ins, Iran. 2004.

19. Mc Guire J. Understanding psychology and Crime: Perspective on theory and action. Open University Press, USA. 2006. p.68-75.
20. Thornton B, Pickus J, Aldrich M. Ways of coping in relationship and achievement situations: Further consideration of gender and gender-role typing. J worry Affect Exp. 2005;2:60-70.

21. Matthews G, Schwean VL, Campbell SE, et al. Personality, selfregulation, and adaptation. In: Boekaerts $\mathrm{M}$, Pintrich PR, Zeidner M (Eds.), Handbook of self-regulation san Diego, Academic press, USA. 2011. p.45-49.

22. Erikson E. Childhood and Society. Penguin Random House, UK. 1963. p.1-431.

23. American Academy of Child and Adolescent Psychiatry. Practice parameter for the assessment and treatment of children and adolescents with suicidal behavior. J Am Acad Child Adolesc Psychiatry.2011;40(7 Suppl):24S-57S 